\title{
Protective SiC Coating on Carbon Fibers by Low Pressure Chemical Vapor Deposition
}

\author{
Hyun Jeong Bae ${ }^{1}$, Baek Hyun Kim ${ }^{1}$ and Do-Kyun Kwon ${ }^{1 \dagger}$ \\ ${ }^{1}$ Department of materials Engineering, Korea Aerospace University, Goyang-city, Gyenggi-do, Korea
}

(Received August 5, 2013 : Received in revised form November 13, 2013 : Accepted November 18, 2013)

\begin{abstract}
High-quality $\beta$-silicon carbide $(\mathrm{SiC})$ coatings are expected to prevent the oxidation degradation of carbon fibers in carbon fiber/silicon carbide $(\mathrm{C} / \mathrm{SiC})$ composites at high temperature. Uniform and dense $\beta$-SiC coatings were deposited on carbon fibers by low-pressure chemical vapor deposition (LP-CVD) using silane $\left(\mathrm{SiH}_{4}\right)$ and acetylene $\left(\mathrm{C}_{2} \mathrm{H}_{2}\right)$ as source gases which were carried by hydrogen gas. SiC coating layers with nanometer scale microstructures were obtained by optimization of the processing parameters considering deposition mechanisms. The thickness and morphology of $\beta$-SiC coatings can be controlled by adjustment of the amount of source gas flow, the mean velocity of the gas flow, and deposition time. XRD and FE-SEM analyses showed that dense and crack-free $\beta$-SiC coating layers are crystallized in $\beta$-SiC structure with a thickness of around 2 micrometers depending on the processing parameters. The fine and dense microstructures with micrometer level thickness of the $\mathrm{SiC}$ coating layers are anticipated to effectively protect carbon fibers against the oxidation at high-temperatures.
\end{abstract}

Key words silicon carbide, low pressure chemical-vapor deposition(lp-cvd), carbon-fiber, microstructure, boundary layer.

\section{Introduction}

Carbon fiber/Silicon Carbide $(\mathrm{C} / \mathrm{SiC})$ composites have received much attention in recent years. Their good mechanical, thermal and chemical properties, especially from the point of view of property/weight and property/ cost ratios, make these materials widely applicable in many fields. ${ }^{1)}$ However, the applications of $\mathrm{C} / \mathrm{SiC}$ composites as high-temperature material have been mostly limited to inert atmosphere due to the oxidation degradation of carbon fiber. ${ }^{2,3)}$ Once the interfacial bond between fiber and matrix has been damaged by oxidation, a significant reduction in mechanical properties of the composite is unavoidable. ${ }^{4)}$ In the development of the oxidation protection of carbon fibers, silicon carbide( $\mathrm{SiC})$ coatings have been considered to be one of the best candidates, due to its effectiveness in the oxidation resistance and the suppression of the inter-diffusion and possible chemical reactions between carbon fiber and matrix. ${ }^{5-7)}$ Various methods have been developed to prepare $\mathrm{SiC}$ coating on carbon fibers, such as carbo-thermal reduction ${ }^{8-11)}$ and chemical vapor deposition(CVD). ${ }^{12-18)}$ The carbo-thermal reduction technique is simple and easy to operate, and the coatings prepared are generally compatible well with carbon fibers. However, it suffers from several drawbacks. It requires very high temperature $\left(1400-1650{ }^{\circ} \mathrm{C}\right)$ to reduce $\mathrm{SiO}_{2}$ to $\mathrm{SiC}$, and some carbon (C) from carbon fibers is consumed by the reduction reaction and converted to $\mathrm{CO} / \mathrm{CO}_{2}$, which, in addition to causing the carbon loss, may potentially damage the structure of carbon fibers and thus negatively affect their properties. Compared to the carbo-thermal reduction technique, the CVD technique can enable $\mathrm{SiC}$ coatings prepared at much lower temperatures $\left(800-1250^{\circ} \mathrm{C}\right)$. Moreover, it is a continuous and relatively rapid process. ${ }^{19)}$ It offers relatively high deposition rate and provides the possibility of depositing uniform layers on the individual monofilaments of a fiber bundle without bridge bonding if the reaction parameters are carefully controlled. ${ }^{20)}$ Generally, for the preparation of $\mathrm{SiC}$ coated carbon fibers, Methyltrichlorosilane $\left(\mathrm{CH}_{3} \mathrm{SiCl}_{3}\right.$ or MTS) was employed because it contains the same number of silicon and carbon atoms in one MTS molecule and thus can easily prepare stoichiometric silicon carbon. ${ }^{21-24)}$ Yet this process also is carried out in the temperature range of $900-1400{ }^{\circ} \mathrm{C}$ and at total pressure of 10-50 torr in a hydrogen atmos-

\footnotetext{
${ }^{\dagger}$ Corresponding author

E-Mail : dkwon@kau.ac.kr (D.-K. Kwon, Korea Aerospace Univ.)
}

(C) Materials Research Society of Korea, All rights reserved.

This is an Open-Access article distributed under the terms of the Creative Commons Attribution Non-Commercial License (http://creativecommons.org/licenses/by-nc/3.0) which permits unrestricted non-commercial use, distribution, and reproduction in any medium, provided the original work is properly cited. 
phere. $^{25)}$ Another common used SiC deposition system is based on the reaction of silane $\left(\mathrm{SiH}_{4}\right)$ with a hydrocarbon such as propane $\left(\mathrm{C}_{2} \mathrm{H}_{8}\right)$, ethylene $\left(\mathrm{C}_{2} \mathrm{H}_{4}\right)$ and acetylene $\left(\mathrm{C}_{2} \mathrm{H}_{2}\right)$. The deposition temperature of reaction system using $\mathrm{SiH}_{4}$ and $\mathrm{C}_{2} \mathrm{H}_{2}$ as the reactant gases that form $\mathrm{SiC}$ deposition layers is lower than that using MTS. ${ }^{25)}$ In this paper, we report a CVD reaction system using $\mathrm{SiH}_{4}$ and $\mathrm{C}_{2} \mathrm{H}_{2}$ as the reactant source gases that form $\beta$-SiC deposition layers on carbon fibers at deposition temperature $1100{ }^{\circ} \mathrm{C}$. By using tubular reactors which have moderate volume and temperature, the thickness and morphology of $\beta$-SiC deposition layers can be controlled by regulating the source flow rate and different deposition time.

\section{Experimental procedure}

$\beta$-SiC coatings on carbon fibers were deposited by the low pressure chemical vapor deposition(LPCVD) in a horizontal hot-wall reactor. Fig. 1 shows a schematic diagram of a LPCVD system. The diameter of the quartz tube(reactors) was varied from $\varnothing 60$ to $\varnothing 130$ inner diameter and the length of the quartz tube was $1 \mathrm{~m}$ (gas inlet $=\varnothing 10)$. Using $\mathrm{H}_{2}$ as the carrier gas, silane $\left(\mathrm{SiH}_{4}\right.$, purity $99.9999 \mathrm{wt} \%)$ and acetylene $\left(\mathrm{C}_{2} \mathrm{H}_{2}\right.$, purity 99.9 $\mathrm{wt} \%$ ) source gases were premixed and sent through tubular hot-wall reactors. Carbon fibers with a diameter of about 6-7 $\mu \mathrm{m}$ (C-520, Muhan composite, tensile modulus was $235 \mathrm{GPa}$, tensile strength was $4.354 \mathrm{GPa}$, density was $1.795 \mathrm{~g} / \mathrm{cm}^{3}$ ) were used as substrates. They were cleaned with methyl alcohol and deionized(DI) water and then dried at $100{ }^{\circ} \mathrm{C}$ in an oven prior to deposition.

The deposition temperature, flow ratio of the reactant gases $\left(\mathrm{SiH}_{4}: \mathrm{C}_{2} \mathrm{H}_{2}\right)$, carrier gas $\left(\mathrm{H}_{2}\right)$ flow were fixed, while other parameters such as deposition time, amount and mean velocity of source gas flows, were varied to figure out the effect of processing parameters on the microstructural evolution of the deposited SiC layers. The mean velocity of the source gas flow was controlled

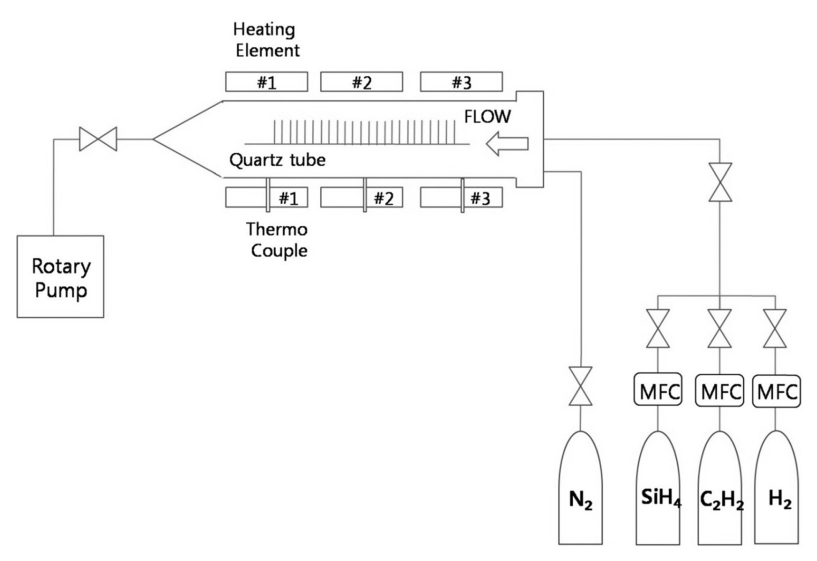

Fig. 1. Schematic diagram of LP-CVD system. by altering the reactor tubes with different diameters.

The phase identification and crystal structure of the deposited layer on the carbon fibers were examined by Xray diffraction (XRD, Ultima $\mathrm{IV}$ ) using $\mathrm{Cu}-\mathrm{K} \alpha$ radiation $(\lambda=1.54056 \AA)$. The working voltage and current of the $\mathrm{Cu}$ target were $40 \mathrm{kV}$ and $40 \mathrm{~mA}$, respectively. The field emission scanning electron microscope (FE-SEM, JSM$6701 \mathrm{~F}$ ) was employed to analyze morphology and thickness of the deposited SiC layers.

\section{Result and Discussion}

Fig. 2(a) and (b) show XRD profiles bare and SiC deposited carbon fibers, respectively. The XRD pattern of bare fibers shows only one peak at about $2 \theta=26.4^{\circ}$, which indexed as (002) diffraction plane of carbon. ${ }^{26)}$ For $\mathrm{SiC}$ covered fibers, three additional peaks at $2 \theta=35.6^{\circ}$, $60.0^{\circ}$ and $71.8^{\circ}$ were observed, which correspond to the (111), (220) and (311) diffraction planes of cubic $\beta$-SiC. This confirms that the $\mathrm{SiC}$ layers deposited on the carbon fibers were crystallized as $\beta$-SiC at the deposition temperature of $1100{ }^{\circ} \mathrm{C}$.

The microstructure of the $\mathrm{SiC}$ coating layer grown by CVD on carbon fiber was affected by characteristics of source gas flows, which includes source gas concentration and mean velocity of the gas flow. Fig. 3 shows the surface morphologies of $\beta$-SiC thin films on carbon fibers deposited at $1100{ }^{\circ} \mathrm{C}$ with different amounts of

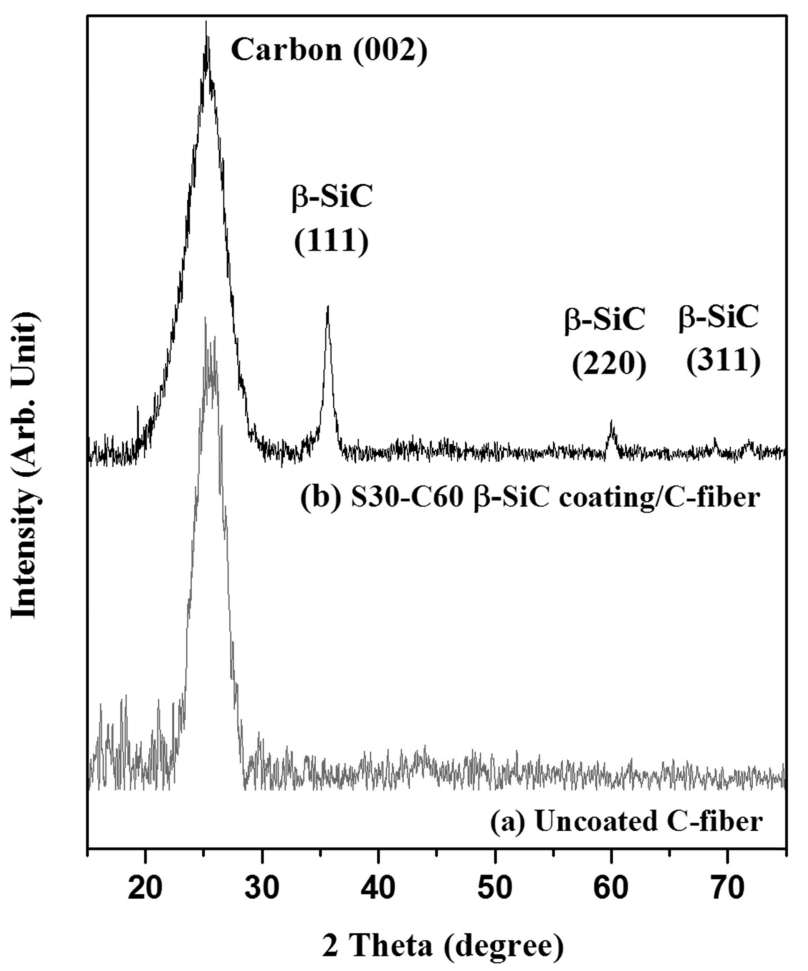

Fig. 2. X-ray diffraction profiles of (a) bare and (b) SiC deposited carbon fibers. 

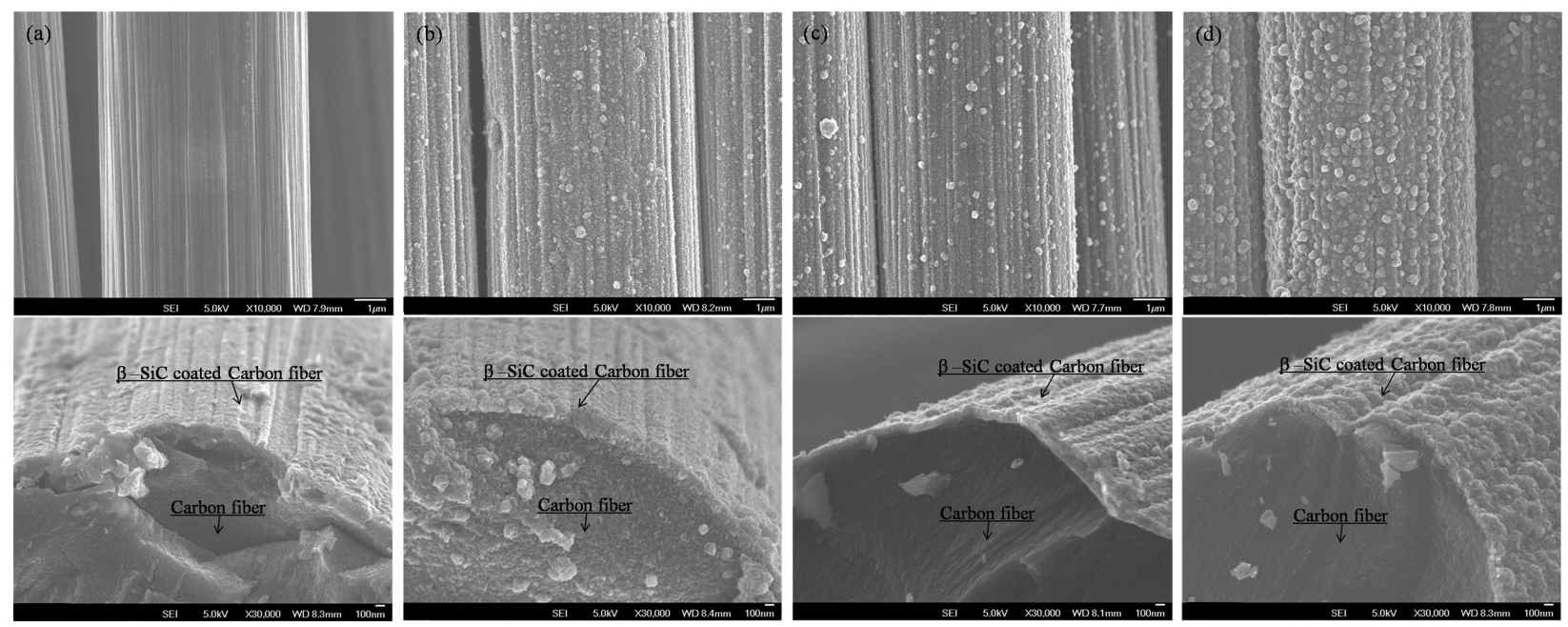

Fig. 3. FE-SEM images of the surface morphologies of $\beta$-SiC thin films on carbon fibers deposited at different source gas flows. (Deposition time: 1 hr). (a) $\mathrm{SiH}_{4}: \mathrm{C}_{2} \mathrm{H}_{2} 5: 10$ (b) $\mathrm{SiH}_{4}: \mathrm{C}_{2} \mathrm{H}_{2} 10: 20$ (c) $\mathrm{SiH}_{4}: \mathrm{C}_{2} \mathrm{H}_{2} 20: 40$ (d) $\mathrm{SiH}_{4}: \mathrm{C}_{2} \mathrm{H}_{2} 30: 60$.

source gas flows. The gas concentration could be adjusted by controlling the amount of source gases $\left(\mathrm{SiH}_{4}\right.$ and $\left.\mathrm{C}_{2} \mathrm{H}_{2}\right)$ flow with constant carrier gas $\left(\mathrm{H}_{2}\right)$ flux. With increase in source gas flux $\left(\mathrm{SiH}_{4}: \mathrm{C}_{2} \mathrm{H}_{2}\right)$ from $5 \mathrm{sccm}: 10 \mathrm{sccm}$ to 30 $\mathrm{sccm}: 60 \mathrm{sccm}$, it can be seen that the smooth surface of carbon fiber with thin $\beta$-SiC film were changed to rough surface consisting of larger grains. Meanwhile, no obvious change in film thickness has been observed by increasing the source gas flows. Thickness changes of the $\mathrm{SiC}$ deposited layers and average grain sizes with different input gas flows are presented in Fig. 4. The film thickness independency on the amount of source gas flow can be explained by postulating that the reactants become supersaturated. Because the supersaturating condition impedes nucleation, the thickness of $\beta$-SiC coating layers changes rarely and $\beta$-SiC grains can grow larger over time. ${ }^{27)}$ Hence the deposition rate also is saturated.

The effects of mean velocity of the gas flow are ex-

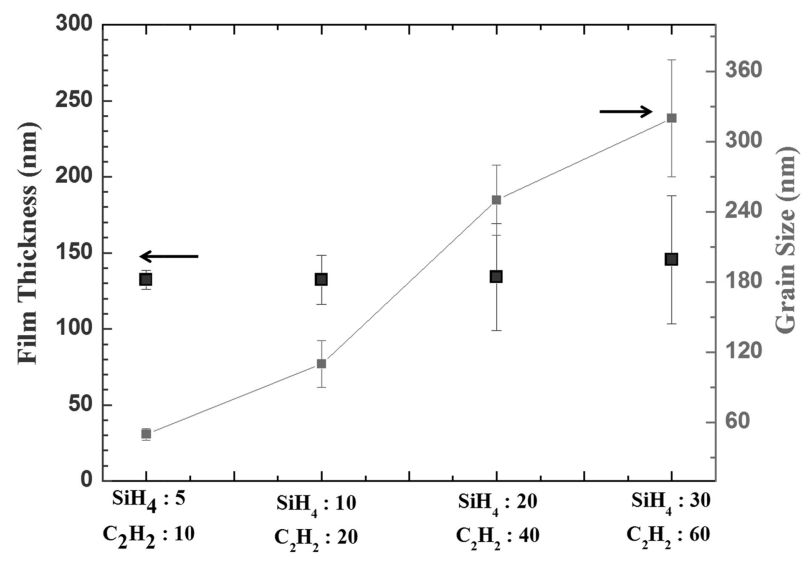

Gas flow rate (sccm)

Fig. 4. Thickness changes of $\beta$-SiC thin fims and average $\beta$-SiC grain sizes with different source gas flows. hibited in Fig. 5. The mean velocity of the gas flow in the horizontal hot-wall tube type LP-CVD reactors could be expressed as

$$
v_{g}=J R T^{\prime} / A P_{t o t}
$$

where, $T^{\prime}$ is the local temperature of the substrate, $J$ is the molar flow rate of carrier gas, $P_{\text {tot }}$ is the total pressure, $A$ is the cross-section area of the tube, and $R$ is gas constant. ${ }^{28)}$ Therefore, the mean velocity of the gas flow is proportional to $1 / d^{2}$, where $d$ is the tube diameter. In the current work, we prepared two sets of LP-CVD SiC samples, which were deposited in tube reactors of different diameters, $130 \mathrm{~mm}(\varnothing \mathbf{\varnothing} 130)$ and $60 \mathrm{~mm}($ ( 60), respectively. Since other deposition conditions including input gas flow rate, pressure and temperature are fixed, the mean velocity of the gas flow in $\boldsymbol{\emptyset} 60$ tube reactor is approximately over 4 times faster than that in $\varnothing 130$ tube reactor, according to Eq. (1). As shown in Fig. 5, LP-CVD process in $\boldsymbol{\emptyset} 60$ tube reactor produced much thicker $\mathrm{SiC}$ coating layer on the carbon fibers. Though the deposition rate increased in faster gas flow, the dense and homogeneous surface morphology with nanometer scale grain size and pore free microstructure is still maintained.

In explaining the effects of mean velocity of the gas flow to the deposition rate and the microstructure, it is necessary to understand the mechanisms of the CVD. The deposition in the tube-type hot wall reactor with source gas flows at elevating temperature occurs in 4 steps, which are (1) transport of source gas by a forced flow of carrier gas, (2) diffusion of source vapor from the gas phase onto receiving substrates, (3) migration and surface reaction of the absorbed species, (4) desorption of the excess absorbed species into the gas phase. Generally, the rate determining step could be either the diffusion or the surface reaction, 

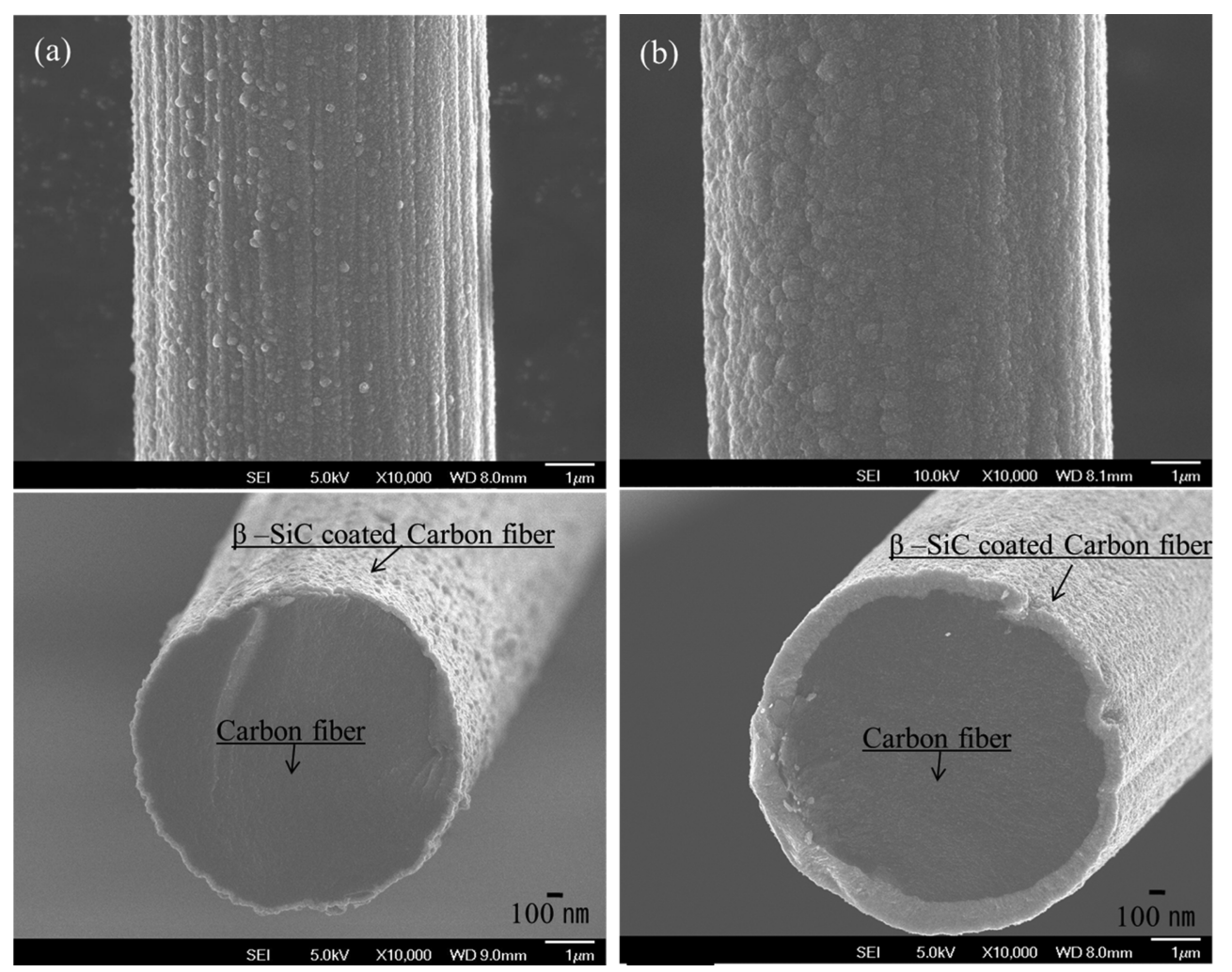

Fig. 5. FE-SEM images of $\beta-\mathrm{SiC}$ coated carbon fibers deposited at (a) Ø 130 inner diameter and (b) Ø 60 inner diameter of the reactor $\left(\mathrm{SiH}_{4}: \mathrm{C}_{2} \mathrm{H}_{2} 10: 20\right.$, deposition time : $\left.1 \mathrm{hr}\right)$.

which is referred to as diffusion-limited or surface reactionlimited process, mostly depending on deposition temperature. The CVD-SiC process at $1100{ }^{\circ} \mathrm{C}$ is reported as diffusion-limited process, which is directly influenced by the diffusion through the boundary layer of the gas flow. ${ }^{25}$ )

In the hot-wall tube reactor, the gas flow could be regarded as a laminar flow, as the dimensionless parameter Reynolds number, which characterizes the flow of a fluid, is low enough. In the case of laminar flow, the velocity of the input gas flow at the deposition surface of substrate is zero due to friction between the gas flow and the substrate. The difference between the flow velocities at the substrate surface and the bulk gas flow gives rise to a boundary layer in which the flow velocity evolves from zero to that of the bulk gas flow. ${ }^{28)}$ The thickness of the boundary layer $(\delta)$ is related to the Reynolds number and varies with the lateral distance away from the edge of the substrate as

$$
\delta=\frac{x}{\sqrt{R e}}
$$

The Reynolds number is

$$
R e_{x}=\frac{\rho_{g} v_{g} \mathrm{~d}}{\mu_{g}}
$$

Where $\rho_{\mathrm{g}}, v_{\mathrm{g}}$, and $\mu_{\mathrm{g}}$ are the input gas density, mean velocity of the gas flow, and dynamic viscosity of the gas flow, respectively, and $\mathrm{d}$ is the diameter of the reactor. The diffusion process is essentially a transport of reactant vapor through boundary layer. The boundary layer thickness $(\delta)$ indicates diffusion length of the reactant vapor species from the bulk gas flow to the deposition sites. ${ }^{25)}$ Therefore, the deposition rate can be accelerated by decreasing the boundary layer thickness in the diffusionlimited process. As expressed in Eq. (2) and (3), the thickness of the boundary layer $(\delta)$ is inversely depends on the mean velocity of the gas flow $\left(v_{g}\right)$, and the reduced boundary layer thickness due to the faster gas flow resulted in thicker deposition layer during the same deposition time, as shown in Fig. 5. The fine and uniform microstructure of the both samples in Fig. 5(a) and (b) alludes that the deposition process in these conditions are still diffusion-limited. However, further reduction in boundary layer thickness may switch the process into reactionlimited process where the boundary layer diffusion plays a negligible role. In such conditions, the diffusion flux is larger than the kinetics of the surface reaction, and the excess amount of absorbed species may aggregate and cause poor surface microstructure, as exhibited in Fig. 3(d) $2 \mu \mathrm{m}$ thick dense $\mathrm{SiC}$ layers on carbon fiber could be fabricated by extended deposition process for 3 hours, as exhibited in Fig. 6(b). The results showed that the 

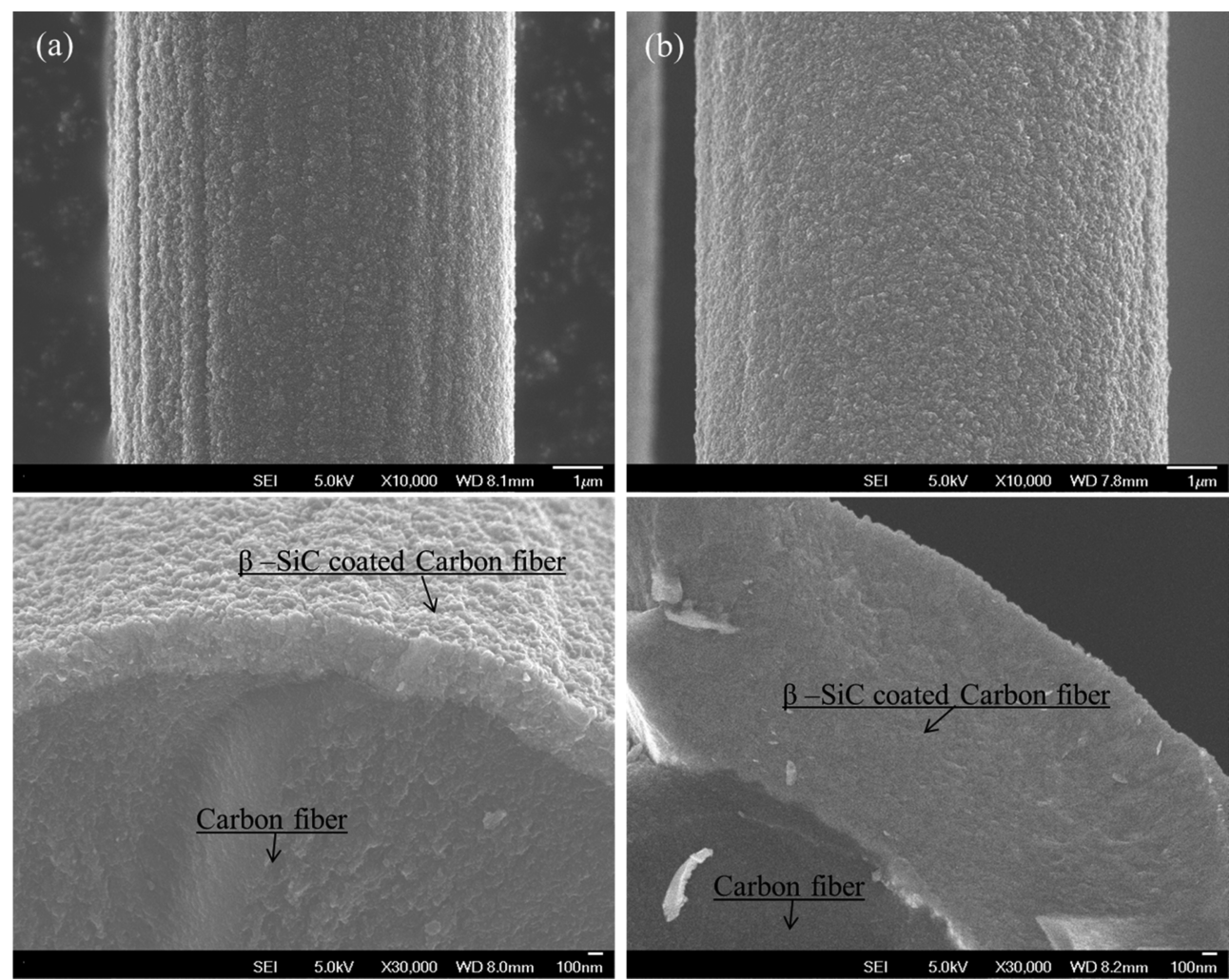

Fig. 6. Thickness changes of $\beta$-SiC films deposited at $\varnothing 60$ inner diameter of the reactor with different deposition times (a) $1 \mathrm{hr}$ and (b) $3 \mathrm{hr}\left(\mathrm{SiH}_{4}: \mathrm{C}_{2} \mathrm{H}_{2} 10: 20\right)$.

deposition time directly influenced to the thickness of the deposited layer without changing microstructure. The fine and dense microstructure with micrometer level thickness of the $\mathrm{SiC}$ coating layer is anticipated to effectively protect the carbon fiber against the oxidation in hightemperature atmosphere.

\section{Conclusion}

The dense and uniform $\beta$-SiC coating layers were formed on carbon fibers by LP-CVD utilizing $\mathrm{SiH}_{4}$ and $\mathrm{C}_{2} \mathrm{H}_{2}$ as reactant gases at $1100{ }^{\circ} \mathrm{C}$. The deposition rate and microstructure of the deposited layer are subjected to influences of diffusion of the source material vapor through the boundary layer of gas flow at the deposition temperature. Reduced boundary layer thickness by controlling mean velocity of the gas flow promoted the diffusion process, which resulted in improved deposition rate while maintaining dense and fine microstructure. Resulting $\mathrm{SiC}$ covered carbon fibers which were fabricated through the LP-CVD process at $1100{ }^{\circ} \mathrm{C}$ for $3 \mathrm{hr}$ showed very dense microstructure with nanometer scale fine grains and micrometer level thickness. The thick and dense SiC coating layer is expected to effectively protect the inner carbon fiber from both chemical attacks during the $\mathrm{C}-\mathrm{SiC}$ composite fabrication process and oxidation events when it was exposed to oxidizing environments at high temperature.

\section{Acknowledgement}

This work was supported by Defense Acquisition Program Administration and Agency for Defense Development under the contract UD110093CD.

\section{Reference}

1. Y. Xu, L. Cheng and L. Zhang, et al., Mater. Sci. Eng., 300, 196 (2001).

2. Y. Yin, J. G. Binner and T. E. Cross, et al., J. Mater. Sci., 29, 2250 (1994).

3. L. R. Zhao and B. Z. Jang, J. Mater. Sci., 32, 2811 (1997).

4. Y. Yin, J. G. Binner, T. E. Cross, et al., J. Mater. Sci., 29, 2250 (1994).

5. Y. Q. Wang, B. L. Zhou and Z. M. Wang, Carbon, 33(4), 427 (1995).

6. T. Piquero, H. Vincent, C. Vincent and J. Bouix, Carbon, 33(4), 455 (1995).

7. K. Kusakabe, B. K. Sea, J. I. Hayashi, H. Maeda and S. Morooka, Carbon, 34(2), 179 (1996).

8. K. L. Choy, Prog. Mater. Sci., 48(2), 57 (2003).

9. G. Hackl, H. Gerhard and N. Popovska, Thin Solid Films, 513(1-2), 217 (2006). 
10. Y. J. Lee, Diam. Relat. Mat., 13(3), 383 (2004).

11. T. Shimoo, K. Okamura, T. Akizuki and M. Take mura, J. Mater. Sci., 30(13), 3387 (1995).

12. G. Emig, N. Popovska and G. Schoch, Thin Solid Films, 241, 361 (1993).

13. K. Kusakabe, B. Sea, J. Hayashi, H. Maeda and S. Morooka, Carbon, 34(2), 179 (1996).

14. G. Emig, N. Popovska and G. Schoch, Thin Solid Films, 241, 361 (1993).

15. T. Piquero, H. Vincent, C. Vincent and J. Bouix, Carbon, 33(4), 455 (1995).

16. Y. Wang, Z. Wang, B. Zhou and C. Shi, J. Mater. Sci. Lett., 12, 817 (1993).

17. G. Hackl, H. Gerhard and N. Popovska, Thin Solid Films, 513, 217 (2006).

18. Y. Wang, B. Zhou and Z. Wang, Carbon, 33(4), 427 (1995).

19. W. Xie, Z. Mirza, G. Mobus, and S. Zhang, J. Am. Ceram. Soc., 95(6), 1878 (2012).
20. J. Schlichting, Powder Metall. Int., 12(3-4), 141 (1980).

21. D. P. Stinton, W. J. Lackey, R. J. Lauf and T. M. Besmann, Ceram. Eng. Sci. Proc., 5, 668 (1984).

22. K. Minato and K. Fukuda, J. Mater. Sci., 23, 699 (1988)

23. D. Lespiaux, F. Langlasis and R. Naslain, J. Mater. Sci., 30, 1550 (1995).

24. W. J. Lackey, J. A. Hanigofsky, G. B. Freeman, R. D. Hardin and A. Prasad, J. Am. Ceram. Soc., 78, 1564 (1995).

25. H. O. Pierson, Handbook of Chemical Vapor Deposition, 2nd Edition: Principles, Technology and Applications, $\left(2^{\text {nd }}\right.$ edition, Noyes, New York, 1992), Chap. 9.

26. Powder diffraction file, Joint Committee on Powder Diffraction Standard, Card 12-0212.

27. M. G. So and J. S. Chun, J. Vac. Sci. Technol. A, 6(1), 5 (1988).

28. C. Li, L. Huang, G. P. Snigdha, Y. Yu and L. Cao, ACS Nano, 6(10), 8868 (2012). 